\title{
CARGAS DE TRABALHO E AS INTER-RELAÇÕES COM O PROGRAMA DE HUMANIZAÇÃO DO PRÉ-NATAL E NASCIMENTO*
}

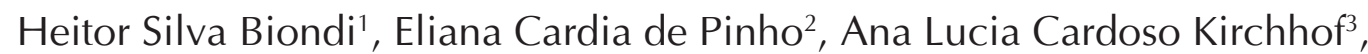 \\ Laurelize Pereira Rocha ${ }^{4}$, Nalú Pereira da Costa Kerber
}

\begin{abstract}
RESUMO: Objetivo: conhecer a inter-relação entre a implementação de práticas assistenciais, propostas no Programa de Humanização do Pré-Natal e Nascimento, e as cargas de trabalho presentes no processo de trabalho de enfermeiros em Centros Obstétricos e Maternidades. Método: qualitativo e descritivo, desenvolvido com 14 enfermeiros em dois Centros Obstétricos e Maternidades de dois hospitais do sul do Brasil. Dados coletados de outubro de 2015 a janeiro de 2016, através de entrevista semiestruturada, explorados com base na Análise de Conteúdo. Resultados: emergiram duas categorias: 'A atenuação das cargas de trabalho', na qual se destacam as cargas de trabalho biológicas e psíquicas, e 'A potencialização das cargas de trabalho', sendo elencadas as cargas de trabalho biológicas, mecânicas e psíquicas. Conclusão: a forma e o contexto como se processam as cargas de trabalho levam-nas a ser atenuadas ou potencializadas na implementação de práticas propostas no Programa de Humanização do Pré-Natal e Nascimento.

DESCRITORES: Carga de trabalho; Parto humanizado; Administração de serviços de saúde; Assistência perinatal;

Enfermagem.
\end{abstract}

\section{WORKLOADS AND INTERRELATIONSHIPS WITH THE PROGRAM FOR THE HUMANIZATION OF PRENATAL AND CHILDBIRTH CARE}

\begin{abstract}
Objective: to learn the interrelationship between the implementation of care practices proposed in the Program for the Humanization of Prenatal and Childbirth Care and the workloads in the work process of nurses in obstetrics centers and maternity hospitals. Method: a qualitative and descriptive study was carried out with 14 nurses at two obstetrics and maternity centers of two hospitals in southern Brazil. Data were gathered from October 2015 to January 2016 through semi-structured interviews, explored with content analysis. Results: two categories emerged: 'Attenuation of workloads', in which biological and psychic workloads stand out, and 'Amplification of workloads', with biological, mechanic and psychic workloads standing out. Conclusion: the way and context in which workloads are processed make them attenuated or amplified when implementing practices proposed in the Program for the Humanization of Prenatal and Childbirth Care.
\end{abstract}

DESCRIPTORS: Workload; Humanizing delivery; Health services administration; Perinatal care; Nursing.

\section{CARGAS DE TRABAJO E INTERRELACIONES CON EL PROGRAMA DE HUMANIZACIÓN DEL PRENATAL Y NACIMIENTO}

RESUMEN:> Objetivo: Conocer la interrelación entre implementación de prácticas asistenciales propuestas en el Programa de Humanización del Prenatal y Nacimiento, y cargas de trabajo existentes en el proceso de trabajo de enfermeros en Centros Obstétricos y Maternidades. Método: Cualitativo y descriptivo, desarrollado con 14 enfermeros en dos Centros Obstétricos y Maternidades de dos hospitales del sur de Brasil. Datos recolectados de octubre de 2015 a enero de 2016 mediante entrevista semiestructurada, estudiados según Análisis de Contenido. Resultados: Surgieron dos categorías: 'Atenuación de las cargas de trabajo', en la que se destacan las cargas de trabajo biológicas y psíquicas, y 'Potenciación de las cargas de trabajo', mencionando las cargas de trabajo biológicas, mecánicas y psíquicas. Conclusión: La forma y el contexto en los que se procesan las cargas de trabajo llevan a que se atenúen o potencien en la implementación de prácticas propuestas en el Programa de Humanización del Prenatal y Nacimiento.

DESCRIPTORES: Carga de Trabajo; Parto Humanizado; Administración de los Servicios de Salud; Atención Perinatal; Enfermería.

*Artigo extraído da dissertação intitulada: "Inter-relações entre as Cargas de Trabalho presentes no Processo de Trabalho de enfermeiros e a efetivação do Programa Nacional de Humanização no Pré-Natal e Nascimento", apresentada ao Programa de PósGraduação em Enfermagem, da Universidade Federal do Rio Grande, 2016.

${ }^{1}$ Enfermeiro. Mestre em Enfermagem. Hospital Universitário Dro Miguel Riet Correa Júnior, Universidade Federal do Rio Grande. Rio Grande, RS, Brasil.

${ }^{2}$ Enfermeira. Doutora em Enfermagem. Docente no Instituto Federal de Educação, Ciência e Tecnologia do Rio Grande do Sul Campus Rio Grande. Rio Grande, RS, Brasil.

${ }^{3}$ Enfermeira. Doutora em Enfermagem. Universidade Federal de Santa Catarina. Florianópolis, SC, Brasil.

${ }^{4}$ Enfermeira. Doutora em Enfermagem. Universidade Federal do Rio Grande. Rio Grande, RS, Brasil.

Estrada Roberto Socoowisk, 757, casa 57, Vila São João, CEP 96213-000. Rio Grande, RS, Brasil.

E-mail: enf.heitor@gmail.com 


\section{INTRODUÇÃO}

O Programa de Humanização no Pré-Natal e Nascimento (PHPN), lançado em 2000, objetiva reorganizar a assistência ao ciclo gravídico-puerperal, ampliar o acesso e garantir a qualidade, tendo como características o olhar para a integralidade da assistência e a afirmação dos direitos da mulher, incorporadas como diretrizes institucionais. ${ }^{(1)}$

O PHPN permitiu o diálogo requerido sobre a mudança de condutas e procedimentos adotados nos serviços, e da visão destes sobre a mulher, suas necessidades e direitos, visto que o programa prioriza o parto vaginal, a não medicalização e a redução de intervenções, valorizando e dando voz à mulher. ${ }^{(2)}$

Entendendo o PHPN como orientador do Processo de Trabalho (PT) na assistência ao nascimento, tem-se a criação de inúmeras possibilidades para sua concretização, compreendendo o objeto do seu trabalho, a mulher, não mais como um ser passivo, mas como ator principal desta ação. Este se concretiza, dentre outros aspectos, por meio da adoção de novas formas de atuação, como o uso de métodos não farmacológicos para alívio da dor (MNFAD), presença do acompanhante e protagonismo da mulher; e do abandono de condutas inadequadas, como uso rotineiro da ocitocina e posição de litotomia.

No contexto de transformação da assistência podem modificar-se, também, os elementos que interagem constante e dinamicamente entre si e o trabalhador, e que geram desgaste nestes. Tais elementos consistem nas Cargas de Trabalho (CT), compreendidas, neste estudo, com base no referencial de Laurell e Noriega. ${ }^{(3)}$

Segundo o referencial, as CT podem ser divididas em: CT de materialidade externa, como as físicas, químicas, biológicas e mecânicas, que ao interagirem com o corpo produzem desgaste; e CT de materialidade interna, fisiológicas e psíquicas, que materializam-se no corpo ao exprimirem alterações em seus processos internos. ${ }^{(3)}$

O desgaste oriundo das CT se manifestam nos trabalhadores de enfermagem de modo particular, ${ }^{(4)}$ porquanto diferentes tipos de CT estão presentes no PT da enfermagem e podem emergir de distintos contextos, como o contato constante com a dor e o sofrimento, imprevistos da prática assistencial, constante adaptação a novas tecnologias ${ }^{(5)}$ e características do PT, a qual se destaca a divisão parcelar do trabalho e a fragmentação de tarefas sob o controle gerencial do enfermeiro. ${ }^{(6)}$

Ao orientar a assistência desenvolvida em Centros Obstétricos (CO) e Maternidades, alicerçado no abandono do modo tradicional de assistência e de práticas inadequadas, prejudiciais ou ineficazes e o estabelecimento de novas práticas, condutas, posturas e formas de trabalho, o PHPN pode modificar os aspectos que tangenciam as CT neste novo PT que passa a se efetivar.

Entendendo, contudo, que a efetivação do PHPN se dá de modo processual, dependente de aspectos humanos, institucionais, governamentais, dentre outros, considera-se sua implementação atemporal e contínua, marcada por momentos de avanços e retrocessos. Neste contexto variante, distintas CT podem passar a manifestarem-se com maior potencial, enquanto outras podem ser atenuadas.

Na literatura existem estudos que abordam as $C T^{(4-6)}$ e a implementação do $P H P N^{(2)}$, porém, não se encontram pesquisas nacionais e internacionais que articulem os dois aspectos e esclareçam como a implementação das práticas propostas no PHPN inter-relacionam-se com as CT presentes no trabalho dos enfermeiros. Com base no exposto, surge a importância deste estudo, que teve como objetivo: conhecer a inter-relação existente entre a implementação de práticas assistenciais propostas no PHPN e as CT presentes no PT de enfermeiros de COs e Maternidades.

\section{METODOLOGIA}

Estudo qualitativo e descritivo, realizado no $\mathrm{CO}$ e Maternidade de dois hospitais do sul do país, sendo um filantrópico e outro universitário. Participaram 14 enfermeiros, havendo uma perda e uma recusa, no universo total de trabalhadores dos referidos ambientes, uma de cada instituição. 
Foram incluídos os que atuavam unicamente nestes ambientes, há mais de seis meses e não estavam afastados por motivo de férias ou licenças de qualquer natureza. Foram excluídos os que atuavam há menos de seis meses nestes ambientes, não atuavam exclusivamente nestes (sendo sua inserção não contínua e condicionada à cobertura de folgas ou férias) e estavam afastados por motivo de qualquer natureza durante a coleta de dados.

Dados coletados de outubro de 2015 a janeiro de 2016. Os participantes foram contatados pessoalmente, nos turnos e ambientes de trabalho, sendo explicados os objetivos do estudo e demais aspectos pertinentes, procedendo ao convite à participação.

Após a concordância, foi agendado um dia e horário para proceder às entrevistas, que ocorreram no ambiente de trabalho dos enfermeiros, em local privado, sendo reapresentados os objetivos do estudo e assinados os Termos de Consentimento Livre e Esclarecido. Esta foi guiada por roteiro semiestruturado, composto com questões abertas abarcando o foco de interesse do estudo. As mesmas foram gravadas após prévia autorização e, posteriormente, transcritas. O anonimato foi mantido, sendo conferido codinome através da letra ' $E$ ', seguida pela numeração, de acordo com a ordem de realização das entrevistas.

Utilizou-se o método de Análise de Conteúdo ${ }^{(7)}$, com as etapas: pré-análise; exploração do material; tratamento dos resultados e interpretação. Os dados foram categorizados de modo semântico ${ }^{(7)} \mathrm{e}$ explorados com base no referencial de Laurell e Noriega ${ }^{(3)}$ e o PHPN ${ }^{(1)}$.

O estudo obteve parecer favorável sob os números de protocolo 46/2015 e 029/2015 nos Comitês de Ética em Pesquisa na Área da Saúde das instituições Universidade Federal do Rio Grande e Associação de Caridade Santa Casa do Rio Grande, respectivamente.

\section{RESUlTADOS}

Dos 14 participantes, oito enfermeiros atuavam no hospital universitário e seis no hospital filantrópico, nos turnos da manhã, tarde e noite. Todos eram do sexo feminino, com idades entre 24 e 53 anos. Todos realizaram a formação acadêmica, após o lançamento do PHPN.

Nenhum dos participantes possuía especialização na área de Saúde da Mulher, porém, dois estavam cursando. Nove participantes atuavam nos COs e Maternidades por um período inferior a um ano; um atuava há dois anos; dois atuavam há três anos, e dois há mais de cinco anos.

O conteúdo explicitado se revelou homogêneo, não transparecendo particularidades institucionais de filantropia ou serviço público. Logo, as contribuições serão apresentadas conjuntamente.

As falas revelaram distintos aspectos referentes à interação e às influências das CT, apresentados nas categorias abaixo. Para melhor elucidação das inter-relações entre as CT com a implementação do PHPN, estas serão expostas primeiramente na perspectiva da atenuação das CT de materialidade externa e interna e, após isso, serão expostas as CT de materialidade externa e interna que foram potencializadas.

\section{A atenuação das cargas de trabalho}

A implementação do PHPN contribui para o processo de atenuação de distintas CT. Na especificidade das CT de materialidade externa, recebeu destaque a atenuação das ÇT biológicas, enquanto consequência da redução de procedimentos invasivos com potencial de exposição a material biológico:

Das biológicas melhorou, porque toda hora tinha que fazer medicamento e a gente acabava se expondo mais. (E10)

Antes a gente puncionava a paciente quando chegava, e isso nos deixava exposto ao sangue [...]. (E12)

Em relação à CT de materialidade interna, os enfermeiros destacaram a atenuação das CT psíquicas, estando atrelada à satisfação do trabalhador em relação à assistência prestada em conformidade com o PHPN: 
[...] diminuiu, porque sei que eu estou fazendo o que é correto. [...] quando tu sabes o que deve e o que não deve ser feito, fica mais fácil; tu organizas mentalmente, e consegues fazer com que as coisas que não devem acontecer, aconteçam o mínimo possível. (E2)

Me sinto satisfeita porque faço um trabalho bem feito e isso reduz o desgaste psíquico [...] isso é consequência da humanização. [...] quando eu entrei para trabalhar no CO, o enfermeiro executava procedimentos, preenchia documentos, gerenciava e atendia as urgências. Hoje eu presto assistência. Eu acho que a assistência é muito melhor. (E5)

[...] Antes as coisas estavam sendo forçadas e era sofrido também para a gente. A paciente não queria nem olhar para a criança, porque o parto tinha sido tão difícil, doloroso e ela sozinha, sem acompanhante [...] levava a uma cascata de consequências. Agora tu vês muito menos isso. O estresse que isso causava não existe mais. (E10)

A avaliação positiva da mulher e acompanhantes em relação ao cuidado propiciado às mesmas revela-se como atenuador das $\mathrm{CT}$ de materialidade interna psíquicas:

[...] se a paciente for atendida de modo humanizado, sair satisfeita, o familiar sair feliz, a carga psíquica não existe. (E1)

[...] fazer a experiência ser menos traumática possível é muito importante. Isso me motiva a trabalhar com obstetrícia. Ouvir de uma paciente que ela não esperava que o parto dela fosse assim, que doeu, mas que foi bom é o mais recompensador possível. (E2)

As relações interpessoais entre trabalhadores, mulheres e acompanhantes processadas em conformidade com o apregoado pelo PHPN, de forma harmônica e respeitosa, leva à atenuação das CT de materialidade interna psíquicas:

[...] A interação com os familiares é positiva, deixou o trabalho mais prazeroso e fez as coisas fluírem naturalmente. [...] até a interação com a paciente é mais saudável, prazerosa, as coisas são mais tranquilas com a mulher e com o acompanhante. (E10)

[...] As mulheres são mais respeitadas agora e, por isso, tem menos atrito com a família [...] o desgaste psíquico diminui. (E9)

O preparo da mulher para o enfrentamento do parto, ainda durante o pré-natal, elemento preconizado pelo PHPN, confere-Ihe mais autonomia nesta vivência, o que contribui para a atenuação das CT psíquicas:

[...] diminui a carga psíquica, porque tu acabas dispondo de vários períodos para preparar a mulher no pré-natal, com mais assistência e informações. Quando ela chega ao parto, está instruída sobre o que vai acontecer, sabendo como se empoderar. (E2)

[...] as mulheres vem sabendo melhor o que vai acontecer, como vai ser o parto, o que pode ou não fazer e isso ajuda, diminui o desgaste psíquico (E6)

\section{A Potencialização das Cargas de Trabalho}

A implementação do PHPN demonstrou-se potencializador de distintas CT de materialidade externa e interna. Para alguns enfermeiros, a proximidade física existente com as usuárias durante a assistência humanizada acentua as CT de materialidade externa biológicas:

[...] A gente fica mais próximo da mulher, toca nela, pega na mão enquanto tenta incentivar. Se a bolsa estoura quando a gente está ajudando ela a ficar na bola, tu tomas um banho. [...] então, tu te expões mais nas questões biológicas. (E3)

[...] aumenta as biológicas, porque tu não sabes o que aquela paciente tem, se vai entrar em isolamento, e tu já ficou junto, teve contato. (E7)

As CT de materialidade externa mecânicas também foram potencializadas, estando associadas a questões estruturais: 
[...] aumenta a carga mecânica, porque faz mais força para ajudar a mulher. [...] Eu sei que eu estou mal posicionada por questões estruturais. (E5)

[...] A nossa estrutura não ajuda e isso é o que desgasta, pois pra colocar a mulher na bola, eu preciso ajudar ela no equilíbrio, porque não temos barras nas paredes. A gente fica mal posicionada e fazendo força para poder ajudar. (E8)

A resistência de alguns trabalhadores em mudar suas concepções e comportamentos profissionais, visando a atuar em consonância com o PHPN, revela-se como potencializador da CT de materialidade interna psíquica:

[...] Meu desgaste é porque uns conseguem se adaptar e outros não. Parecem pré-históricos que acham que o que aprenderam há anos é o certo. As coisas mudaram. (E11)

[...] me tornar alguém que humaniza [...] entender o quanto eu precisava mudar foi muito desgastante, e perceber o quanto eu mudei me deixa muito feliz. Eu resisti, relutei, e quando eu me dei conta, tinha mudado; perceber em outros essa resistência é desgastante. (E5)

As fragilidades no pré-natal e sua desvinculação com o parto destacam-se como potencializador das CT de materialidade interna psíquicas:

A falta de qualidade do pré-natal traz muito desgastante, pois a mulher vem despreparada para vivenciar aquele momento, e a gente fica correndo contra o tempo para conseguir sanar isso, já com o trabalho de parto acontecendo [...]. (E4)

[...] Tem carteirinha de pré-natal cheia de coisas escritas, mas vazia de coisas relevantes. Não adianta ter 12 consultas num pré-natal mal feito. Isso é desgastante. (E5)

Humanização depende desde a primeira consulta no pré-natal. Elas chegam sem noção do que vai acontecer. Daí tem que explicar tudo e tu tens outras coisas para fazer, não tem como ficar só ali [...]. (E13)

O quantitativo insuficiente de trabalhadores de enfermagem, que se configura como potencializador das CT materialidade externa mecânicas, também se revela como desencadeador de CT materialidade interna psíquicas, em especial quando as atribuições do enfermeiro excedem sua capacidade de executálas. Este desgaste também está relacionado ao aumento das atribuições incluídas ao PT dos enfermeiros na implementação das ações preconizadas pelo PHPN e à necessidade de permanecer junto à paciente e ofertar orientações, em detrimento de outras atividades:

Eu não posso simplesmente prescrever os cuidados. Eu preciso ver essa paciente, conversar, avaliar, examinar; prescrever o que tem de ser feito conforme o programa. Então eu vou destinar mais tempo à paciente. Aumenta o que eu tenho que fazer e o meu desgaste (E1)

[...] dedicar mais tempo para cada paciente [...] atrasa outras coisas; tu deixas de pedir o material, fazer o curativo, [...] Aumenta a carga de trabalho colocar a mulher na bola, fazer teste rápido, cuidar se o acompanhante está bem [...]. (E13)

[...] a medida que a enfermagem assume outras práticas que são preconizadas e que contribuem para parto, eu preciso de mais tempo e de mais pessoal. Se eu tiver esse pessoal é tranquilo, mas se eu não tiver, isso vai sobrecarregar e não vai funcionar. (E14)

\section{DISCUSSÃO}

A atenuação ou potencialização das CT materialidade externa e interna, em virtude da implementação das práticas assistenciais propostas no PHPN, demonstrou-se heterogênea. Todavia, mesmo havendo a participação de enfermeiros de um hospital público e outro filantrópico, não houveram diferenças nos conteúdos elencados. Este fato parece revelar que, mesmo em instituições com características administrativas e de financiamento distintas, os elementos do PT relacionados ao PHPN, que potencializam ou atenuam as CT, são semelhantes. 
Nas falas destacou-se a atenuação das CT de materialidade externa biológicas e a atenuação das CT de materialidade interna psíquicas. As CT de materialidade externa biológicas dizem respeito à possibilidade de exposição e interação com inúmeros microrganismos e vetores com potencial de alterarem ou interferirem negativamente nos processos corporais. (3) Sua atenuação associa-se ao evitamento da implementação de práticas intervencionistas desnecessárias ${ }^{(8)}$ que não beneficiam a mulher nem o recém-nascido e podem trazer maiores riscos. Neste sentido, o alcance da humanização perpassa a redução de intervenções e procedimentos invasivos evitáveis ou desnecessários. ${ }^{(9)}$

Também recebeu destaque a atenuação das CT de materialidade interna psíquicas, que adquirem materialidade através dos processos psíquicos e corporais humanos, ou seja, não possuem existência senão por meio da relação existente entre os trabalhadores e os elementos constitutivos do seu PT, perpassando de aspectos de ambiência. ${ }^{(3)}$ Sua atenuação ocorre pelas relações interpessoais harmoniosas e horizontais entre os agentes envolvidos, essenciais ao processo de humanização. ${ }^{(10)}$

Como coadjuvantes do nascimento, os trabalhadores têm a oportunidade de colocar seu conhecimento a serviço do bem-estar da mulher, bebê e família e, através das interações, minimizar a dor, proporcionar conforto, esclarecer, orientar, ajudando a parir e a nascer, ${ }_{(1)}^{(1)}$ o que se mostra atenuador das CT psíquicas.

OPHPN apregoa o respeito, compreendendo como dever dos serviços de saúde receber com dignidade as usuárias. Isto requer atitude ética e solidária dos trabalhadores e a organização da instituição propícia a um ambiente acolhedor, instituindo rotinas que rompam com o tradicional isolamento imposto à mulher, ${ }^{(8)}$ e que, naturalmente, atenuam as CT psíquicas.

Constatou-se que as CT psíquicas também foram atenuadas pela avaliação positiva da mulher em relação à assistência ofertada, efetivada pelo estímulo ao protagonismo da mesma, respeito à fisiologia do parto e à privacidade dos envolvidos. ${ }^{(11)}$ Medidas de apoio referentes à intermediação e interpretação dos desejos da usuária, acolhendo-os e mediando-os, se necessário ${ }^{(12)}$, são primordiais para a satisfação, sendo as questões clínicas e utilização de tecnologias menos importantes do que a forma como as mulheres são tratadas, apoiadas e o parto é conduzido ${ }^{(13)}$.

A inexecução de práticas não recomendadas, prejudiciais ou ineficazes, revela-se como atenuador das CT psíquicas. Esta é consequência da compreensão dos aspectos científicos orientadores das práticas humanizadas, efetivação do cuidado integral, maior atuação dos enfermeiros na assistência e dos desfechos positivos propiciados por esta forma de assistência.

A articulação do pré-natal com o parto como atenuador das CT psíquicas, associa-se à qualidade das ações educativas desenvolvidas neste, que instrumentalizam a mulher para o parto, empoderando-a e afastando-a de posturas de subordinação.

Em relação à potencialização das $\mathrm{CT}$, receberam destaque as de materialidade externa, biológicas e mecânicas, e as de materialidade interna, psíquicas. Na especificidade da CT biológicas, a potencialização revelou-se relacionada ao contato e à aproximação com a mulher. Porém, tal prática faz-se necessária, pois o contato físico é relevante fator de conforto que transcende as barreiras entre os sujeitos, e estabelece relação de confiança e apoio emocional, criando um ambiente potencializador do poder vital da mulher, facilitando o parto. ${ }^{(14)}$

É papel do enfermeiro a execução do cuidado, podendo este minimizar os possíveis desgastes oriundos das CT biológicas, como os equipamentos de proteção individual, que podem impedir a exposição a patógenos.

Houve potencialização das CT biológicas no contexto da realização dos procedimentos com possibilidade de exposição a fluídos corporais ou maior proximidade física entre o enfermeiro e a mulher. Esta constatação demonstra a compreensão limitada destas cargas, que não estão presentes somente nos momentos de contato entre o trabalhador e a parturiente, mas em todos os ambientes onde a assistência se faz e onde os bens de consumo e utensílios usados na assistência são acondicionados. Revela, ainda, visão fragmentada do PT e de como este é norteado pelo PHPN, porquanto o contato com a parturiente não deve ocorrer de modo mecânico e puramente tecnicista, mas inclui acolhimento, escuta, amparo, educação e instrumentalização para a vivência do parto, que suplantam o contato físico e a exposição a fluídos corporais. 
As CT mecânicas, que são aquelas com potencial para causar lesões no corpo do trabalhador, como contusões, fraturas ${ }^{(3)}$, feridas e lesões em geral ${ }^{(5)}$ e estão intimamente ligadas com as tecnologias utilizadas e condições ambientais ${ }^{(3)}$, também foram potencializadas. Estas estão associadas ao aumento de atividades assistenciais, acentuadas por aspectos estruturais, e ao emprego de ações preconizadas no PHPN, como o uso de MNFAD.

Compreender que há aumento das atividades desenvolvidas pelo enfermeiro pode ser consequência da visão pouco abrangente das diretrizes propostas no PHPN e da fragmentação do PT, onde cada componente da equipe de enfermagem presta parte da assistência separado dos demais, compartimentalizando-a. ${ }^{(6)}$ A potencialização das CT mecânicas neste contexto, perpassa o desenvolvimento do trabalho de modo rotineiro, mecânico e repetitivo, comprometendo a assistência, gerando desgastes físicos e psíquicos e acarretando perda ou a redução da capacidade de produzir. ${ }^{(15)}$

A potencialização das CT psíquicas revelou-se associada à manutenção de práticas não recomendadas pelo PHPN. Vislumbram-se atos de violência obstétrica, cometida através de palavras, expressões de ironia, procedimentos invasivos, condutas inadequadas, coerção e ameaça. ${ }^{(16)}$

Comumente os trabalhadores são autoritários e se apresentam como donos da verdade e do saber, criando barreiras que dificultam a relação de confiança, credibilidade e respeito aos direitos da mulher ${ }^{(17)}$ e também com os acompanhantes, vistos como agentes externos que interferem negativamente no trabalho da equipe ${ }^{(18)}$, contrapondo-se ao PHPN, gerando relações conflituosas e potencializando as CT psíquicas.

Os atos de violência levam a sentimentos de descontentamento e impotência, gerando conflito e angústia. Todavia, tal paradigma contribui para refletir sobre o atendimento que gostariam de oferecer às parturientes, e, consequentemente, procurem um novo caminho de atuação. ${ }^{(16)}$ Este processo de reflexão pessoal, mudança de atitudes e posturas, também pode configurar CT psíquica.

A desarticulação do pré-natal com o parto, igualmente revelada pela literatura(19), intensifica as CT psíquicas devido à falta de registros pertinentes na carteira de pré-natal e despreparo da mulher para as situações a serem enfrentadas, dificultando o exercício da autonomia e dos MNFAD.

Houve potencialização das CT psíquica quando associadas às CT mecânicas, como consequência das atribuições assistenciais e gerenciais do PT dos enfermeiros que suplantam a capacidade de execução destes, levando-os a priorizarem atividades em detrimento de outras, fato acentuado pelo quantitativo de trabalhadores de enfermagem insuficiente, que compromete a qualidade da assistência e a implementação do PHPN.

Conciliar a dimensão assistencial e gerencial do trabalho é o aspecto que leva os enfermeiros a considerarem as CT excessivas. ${ }^{(20)}$ Vislumbra-se, frequentemente, a cisão destas dimensões, comprometendo a assistência e gerando conflitos, seja do profissional com a sua prática, seja nas relações interpessoais. ${ }^{(21)}$ A multiplicidade de funções os impede de desenvolver atividades assistenciais, distanciando-os da finalidade do trabalho do enfermeiro. ${ }^{(22)}$

\section{CONCLUSÃO}

A implementação do PHPN se relaciona com a atenuação e a potencialização das mesmas CT no que tange ao PT dos enfermeiros de COs e Maternidades. Das CT atenuadas, receberam destaque as biológicas, relacionadas à redução de procedimentos invasivos, e as psíquicas, como consequência da inexecução de práticas prejudiciais, relações interpessoais harmoniosas, avaliação positiva da mulher em relação à assistência e percepção de que houve adequado preparo da mulher durante o pré-natal.

Das CT potencializadas, destacaram-se as biológicas, relacionadas à proximidade entre trabalhador e a usuária; as mecânicas, pelo maior esforço e aumento das atribuições; e as psíquicas, como consequência do aumento das atribuições ao enfermeiro, quando estas excedem sua capacidade de executá-las; permanência junto à paciente em detrimento de outras atividades; resistência dos trabalhadores em mudarem suas condutas profissionais; e as consequências das fragilidades do pré-natal para o nascimento. 
A realidade retratada pode apresentar singularidades dos cenários de estudo, suscitando investigações mais abrangentes. Todavia, acredita-se que o universo estudado releva significativos aspectos referentes à atenuação e potencialização das CT no contexto da implementação do PHPN.

Destaca-se a importância de novos estudos na área com vistas ao aprimoramento das estratégias de implementação das políticas públicas de saúde, para que este processo não venha a se tornar potencializador das $\mathrm{CT}$, levando os trabalhadores ao desgaste e adoecimento.

\section{REFERÊNCIAS}

1. Ministério da Saúde (BR). Secretaria de Políticas de Saúde. Área Técnica de Saúde da Mulher. Parto, aborto e puerpério: assistência humanizada à mulher. [Internet] Brasília: Ministério da Saúde; 2001 [acesso em 06 jun 2016]. Disponível: https://www.cintegrado.com.br/site/documentos/parto_aborto_assistencia_mulher.pdf.

2. da Silva RC, Soares MC, Jardim VMR, Kerber NC, Meincke SMK. O discurso e a prática do parto humanizado de adolescentes. Texto contexto - enferm. [Internet] 2013;22(3) [acesso em 02 out 2016]. Disponível: http://dx.doi. org/10.1590/S0104-07072013000300008.

3. Laurell AC, Noriega A. O processo de produção e saúde: trabalho e desgaste operário. São Paulo: Hucitec; 1989.

4. de Carvalho DP, Rocha LP, Barlem JGT, Specht J, Dias CDS, Schallenberger CD. Cargas de Trabalho e a saúde do trabalhador de Enfermagem: Revisão Integrativa. Cogitare Enferm. [Internet] 2017;22(1) [acesso 26 jan 2017]. Disponível: http://dx.doi.org/10.5380/ce.v22i1.46569.

5. Flôr RC, Gelbcke FL. Análise das Cargas de Trabalho decorrentes da práxis da enfermagem em serviço de hemodinâmica. Rev. Enferm. UFPE. [Internet] 2013;7(12) [acesso 26 dez 2016]. Disponível: https://periodicos.ufpe.br/ revistas/revistaenfermagem/article/view/12373.

6. Tavares e Souza MM, Passos JP, Tavares CMM. Sofrimento e precarização do trabalho em enfermagem. J. Res.: fundam. care. [Internet] 2015;7(1) [acesso 02 out 2016]. Disponível: http://dx.doi.org/10.9789/2175-5361.2015. v7i1.2072-2082.

7. Bardin L. Análise de conteúdo. São Paulo: Edições 70; 2011.

8. Ministério da Saúde (BR). Secretaria de Políticas de Saúde. Saúde da Mulher. Assistência ao pré-natal. Manual técnico. [Internet] Brasília: Ministério da Saúde; 2000 [acesso 06 jun 2016]. Disponível: http://bvsms.saude.gov.br/bvs/ publicacoes/cd04_11.pdf.

9. Ferreira Júnior AR, Makuch MY, Osis MJMD, de Barros NF. Percepções de profissionais de enfermagem sobre a humanização em obstetrícia. SANARE Rev. Polit. Públic. [Internet] 2015;14(2) [acesso 16 jun 2016]. Disponível: https:// sanare.emnuvens.com.br/sanare/article/view/821.

10. Possati, AB, Prates LA, Cremonese L, Scarton J, Alves CN, Ressel LB. Humanização do parto: significados e percepções de enfermeiras. Esc. Anna Nery [Internet] 2017;21(4) [acesso 11 maio 2016]. Disponível: http://dx.doi. org/10.1590/2177-9465-ean-2016-0366.

11. Camacho KG, Progianti JM. A transformação da prática obstétrica das enfermeiras na assistência ao parto humanizado. Rev. Eletr. Enf. [Internet] 2013;15(3) [acesso 10 dez 2016]. Disponível: https://doi.org/10.5216/ree.v15i3.18588.

12. Hodnett ED, Gates S, Hofmeyr GJ, Sakala C. Continuous support for women during childbirth. The Cochrane Library. [Internet] 2012;(2) [acesso 03 jul 2016]. Disponível: https://dx.doi.org/10.1002/14651858.CD003766.pub3.

13. Gama AS, Giffin KM, Angulo-Tuesta A, Barbosa GP, d'Orsi E. Representações e experiências das mulheres sobre a assistência ao parto vaginal e cesárea em maternidades pública e privada. Cad. Saúde Pública. [Internet] 2009;25(11) [acesso 05 ago 2016]. Disponível: http://dx.doi.org/10.1590/S0102-311X2009001100017.

14. de Souza MG, de Oliveira CA, Justi J. Puerpério e atenção à saúde: percepção de mulheres assistidas pelo Sistema Único de Saúde. Rev. Saúde e Desenvol. [Internet] 2017;11(7) [acesso 20 out 2017]. Disponível: https://www.uninter. com/revistasaude/index.php/saudeDesenvolvimento/article/view/692/40. 
15. Santana LL, Miranda FMD, Karino ME, Baptista PCP, Felli VEA, Sarquis LMM. Cargas e desgastes de trabalho vivenciados entre trabalhadores de saúde em um hospital de ensino. Rev. Gaúcha Enferm. [Internet] 2013;34(1) [acesso 28 dez 2016]. Disponível: http://dx.doi.org/10.1590/S1983-14472013000100008.

16. Sanfelice CFO, Abbud FSF, Pregnolatto OS, Silva MG, Shimo AKK. Do parto institucionalizado ao parto domiciliar. Rev. Rene. [Internet] 2014;15(2) [acesso 02 jan 2017]. Disponível: http://www.periodicos.ufc.br/rene/article/ view/3170/2433.

17. Bessa LF, Mamede MV. Ação educativa: uma perspectiva para humanização do parto? Revista Baiana de Enfermagem. [Internet] 2010;24(1,2,3) [acesso 10 dez 2016]. Disponível: https://portalseer.ufba.br/index.php/enfermagem/article/ viewFile/5699/4119.

18. Hilana DD, Rodrigues DP, Guerreiro EM, Guedes MVC, do Lago PN, de Mesquita NS. A contribuição do acompanhante para a humanização do parto e nascimento: percepções de puérperas. Esc. Anna Nery [Internet]. 2014;18(2) [acesso 26 maio 2016]. Disponível: http://dx.doi.org/10.5935/1414-8145.20140038.

19. Leal MC, Bittencourt SDA; Torres MRC, Niquini RP, Souza Jr. PRB. Determinantes do óbito infantil no Vale do Jequitinhonha e nas regiões Norte e Nordeste do Brasil. Rev. Saúde Pública. [Internet] 2017;51 [acesso 06 ago 2017]. Disponível: http://dx.doi.org/10.1590/s1518-8787.2017051006391.

20.Mendes RNC, Carmo AFS, Salum RDL, de Gusmão-Filho FAR, Vidal SA, Santos VEP. Dimensionamento de pessoal: avaliação da enfermagem em unidades de terapia intensiva obstétrica e pediátrica mista. R. Pesq.: Cuid. Fundam. [Internet] 2013;5(2) [acesso 02 jan 2017]. Disponível: http://bases.bireme.br/cgi-bin/wxislind.exe/iah/online/?lsisScript=iah/iah. xis\&src=google\&base $=$ LILACS\&lang=p\&nextAction=Ink\&exprSearch=672249\&indexSearch=ID.

21. Lanzoni GMM, Magalhães ALP, Costa VT, Erdmann AL, de Andrade SR, Meirelles BHS. Tornando-se gerente de enfermagem na imbricada e complexa fronteira das dimensões assistencial e gerencial. Rev. Eletr. Enf. [Internet] 2015;17(2) [acesso 29 maio 2016]. Disponível: http://dx.doi.org/10.5216/ree.v17i2.29570.

22. Thofehn MB, Montesinos MJL, Jacondino MB, Fernandes HN, Gallo CMC, Figueira AB. Processo de Trabalho dos Enfermeiros na Produção de saúde em um Hospital Universitário de Múrcia/Espanha. Cienc. Cuid. Saude. [Internet] 2015;14(1) [acesso 30 maio 2016]. Disponível: http://dx.doi.org/10.4025/cienccuidsaude.v14i1.22094. 